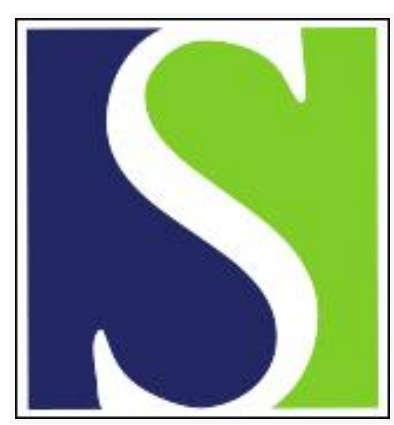

Scand J Work Environ Health 1995;21(3):161-163

https://doi.org/10.5271/sjweh.24

Issue date: Jun 1995

\title{
A look to the past and to the future of research
}

by Hernberg $S$

This article in PubMed: www.ncbi.nlm.nih.gov/pubmed/7481603

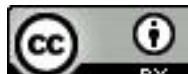

This work is licensed under a Creative Commons Attribution 4.0 International License 


\section{Editorial}

Scand J Work Environ Health 1995:21:161-3

\section{Research, prevention and impact}

In an applied field such as occupational health and safety, the ultimate goal of all research should be to solve problems in work life and to prevent occupational hazards. Not only current problems should be addressed. Ideally, researchers should also try to predict what technology will "bless" us with in the future in order to anticipate problems. If they succeed, relevant knowledge and ready solutions will be available the day the problems appear.

Even in an applied field, basic research can first be needed if sufficient knowledge of the hazard and its effects is lacking. In order for prevention to be effective and focused on the right target, we sometimes need an understanding of the mechanisms that lie behind adverse effects, for example, the toxic action of a chemical, the nature of so-called electric allergy, or the reason why people cannot cope with the explosion of information technology. In many other cases work-related problems can be directly tackled by an applied approach because the basic knowledge needed for their solution already exists. The prevention strategy may be so straightforward that mechanistic knowledge is redundant from the pragmatic point of view. And, finally, very often research is no longer necessary for problem-solving because enough scientific knowledge already exists. The issue is then the implementation of what we already know. Sufficient training of professionals can be the first step of implementation.

Deciding exactly what type of research or what kind of action is optimal in a certain situation depends on careful consideration of all these matters. Basic research, applied research, training of professionals, problemsolving activities, and practical preventive action should go hand in hand, and each should be given its appropriate weight depending on the state of knowledge and the type of action needed. The goal should always be to improve work conditions and ameliorate the workers' health and well-being.

Many brilliant researchers, often deeply specialized in a narrow field, fail to realize that a logical sequence from research to implementation is necessary for research to be useful in society. Remember, today it is no longer prohibited even for basic research to be useful! If research does not lead to significant improvement in relevant knowledge or, even better, to action, the topic may have been wrongly selected or the channels to spread the message and achieve practical results may have been insufficient. With increased public funding, society indeed has the right to demand that research results in something useful.

The Finnish Institute of Occupational Health celebrated its 50th anniversary by organizing an international conference called "From Research to Prevention," a summary of which is reported elsewhere in this issue. The title of the conference was chosen with the aforementioned thoughts in mind. The conference also gave its staff the opportunity to halt to consider the role of a national institute of occupational health in a society in which the values of health and social equality have traditionally been highly rated.

When the Institute was founded in 1945 as a hospital department, our country had just come heavily damaged out of World War II. Although Finland, thanks to heavy sacrifices - 90000 men killed in the war and 200000 wounded out of a population of less than four million - was able to maintain her independence and never became occupied, $12 \%$ of her territory had to be surrendered and $14 \%$ of her population had to be reallocated. In addition, the highest per capita war penalty in world history had to be paid to the Soviet Union in the form of advanced technological products.

Against this background it is a wonder that occupational health was given such high priority in 1945. Only six years later, when the country was still far from recovered, the Institute was opened as we know it today and even moved into a new building. Over the years it developed from a mainly clinical institution to a broad, multidisciplinary research institute, having also professional training and expert service on its agenda. Today it employs 570 persons in one central and six regional institutes. 
Such an organization may seem much for a country whose population today is no more than 5.1 million, of whom about two million are actively employed. However, it must be viewed against the fact that occupational health and safety are poorly represented in the universities and that most of the nation's resources are concentrated in the Institute. The Institute receives $70 \%$ of its annual income of FIM 200 million (USD 45 million) from the state and the rest from its own research, training, information, and service activities. Although the Institute spends no more than FIM 100 (USD 22) annually per active employee, the grand total is so high that society has every right to ask how well this money is being used. The answer requires continuous assessment of the impact of the Institute's activities.

How can the Institute's impact be assessed? It is not enough to count the roughly 400 scientific and 800 popular articles published annually. Neither is the number of biochemical analyses, hygienic surveys, or patients received at the policlinics informative of impact. True, there are nearly 100 staff members holding a doctoral degree, and the country now has more than 400 physicians specialized in occupational health care. The training of professionals is intense, and many textbooks have been published. All this shows a high level of activity, most of it probably very acceptable. But this is predominantly output, not yet necessarily impact.

Impact means that something desirable happens in society at large, and of course also in individual workplaces, as a consequence of the Institute's activities. Examples of such events could be a reduction in the number of work-related diseases and occupational accidents, progress in occupational health legislation and standard setting, improvements in specific work situations or in the average hygienic level of workplaces, for example, reflected by a reduction in the percentage of measurements exceeding the hygienic standards, improved diagnostics, less sickness absenteeism, improved skills of occupational health care personnel, and so forth.

There are many problems in assessing such changes. Reliable statistics of work-related diseases and occupational accidents, for which the inclusion criteria have not changed over the years, are necessary for assessing national trends. Moreover, it is a well known fact that intensified research activities and other campaigns, especially if case-finding and effective training of health personnel are involved, first increase, not decrease, the number of reported cases of the disease in question. Such a trend was especially seen in Finland for lead poisoning and asbestos-related diseases. The same is true if diagnostic methods improve, for example, in the case of solvent poisoning, or if compensation legislation develops towards less stringent criteria, as has been the case for hearing loss. Sickness absenteeism is well-known for its complex nature, reflecting many more aspects than sickness alone. It is a poor measure. Even if registers for hygienic measurements and biological monitoring results exist, unbiased results are difficult to extract from them because the reasons for the measurements can vary. Some workplaces wish to prove that their work conditions are safe, while others try to locate the worst conditions when planning improvements. Sampling strategy may change over the years, and analytical methods also. And, finally, how can one in practice assess the skills of the country's occupational health personnel?

Even if favorable trends could be identified, it is also impossible to give credit to any single party, such as a research institute. An institute of occupational health can influence the field only indirectly because it lacks any regulatory capacity. It works through occupational health services, labor inspection, and decision makers. It can take initiatives, spread knowledge, and train professionals, but, if something favorable happens, it is due to collaboration with many different bodies. In this context one should not forget the impact of modern technology as such. Many dangerous and unhealthy jobs have been eliminated merely thanks to the advances of technology, even though new problems have also been created for the very same reason.

Hence it indeed is difficult to measure a research institute's impact. With these reservations in mind, it is interesting that a recent inventory estimated that in at least 20 cases a work-related disease had been prevented, new hazardous exposures had been identified, or a major ergonomic improvement had been implemented primarily thanks to the Institute's initiatives and activities during the last decade. The Institute had further been involved in developing about 250 technical solutions, such as protective clothing, improved work tools, software design, and the like, aimed at providing better work conditions. Of course the share of others has been significant in all of these activities, but would these actions have taken place without the Institute's contribution? 
In this mosaic of so-called impact, research has always played a key role. Research has laid the foundation for any impact. Besides providing results directly applicable to Finnish work life, the Institute's research activities have helped create broad competence among its staff. Against this background it is strange that one, especially earlier, often heard the statement - even from "responsible" decision makers - that a small country does not need to do much research itself; it is sufficient to import the knowledge arising from research done elsewhere. The advocates of this short-sighted view fail to realize that research results cannot be imported if there is no one at the receiving end capable of understanding and applying them. Without own research activity, neither understanding nor application is possible. Moreover, acceptance as a member of international joint research programs or any other form of international interaction is out of reach if one cannot contribute oneself.

In the early years of the Institute's existence, research was "free." This policy clearly resulted in too little impact. In the early 1970s it was changed, not the least because of strong societal pressure. Written programs, drafted by the research committee after hearing senior researchers and approved by the Board of Directors, began to state guidelines for setting priorities for the Institute's research. Since then, the policy has been rewritten three times, and much attention has been paid to formulating the criteria for selecting research topics. According to the latest program, dated 1988, attention must be paid not only to the scientific significance of the problem, but also to whether it is severe, widespread, and increasing in frequency and severity. The means for applying the results in practical occupational safety and health work must also be considered. During the last few years quality assurance has entered the scene, and there are now also written guidelines for achieving research of high quality. In these guidelines much emphasis is also placed on the choice of the topic of research and the evaluation of its scientific and societal relevance.

Much has happened in 50 years. Today we face new challenges. The emphasis of occupational health is now clearly moving towards "softer" problems, such as the psychosocial work environment, musculoskeletal disorders, work with computers, teachers' and health care personnel's problems, and so forth. This shift in direction requires a new kind of competence and new research approaches. Yet we still have to tackle conventional problems, such as work-related cancer, allergies, dermatoses, and many classical occupational diseases. Accidents still occur. New chemicals are being introduced, and there is concern for their influence on fertility, their carcinogenicity, and other ill-defined long-term effects. For a national institute that is responsible for covering the whole field, the new panorama means that the spectrum of competence must become broader; however, it also means that difficult decisions have to be made about the kind of traditional research that must be tuned down or abandoned. A research institute that cannot adapt to new challenges will soon become a former research institute. I have no doubt that the Finnish Institute of Occupational Health will be capable of entering its second half-century with a fresh mind.

Sven Hernberg, MD 